\title{
Novel lncRNA-ZNF281 regulates cell growth, stemness and invasion of glioma stem-like U251s cells
}

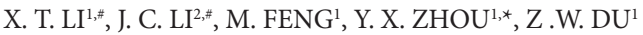 \\ ${ }^{1}$ Department of Neurosurgery \& Brain and Nerve Research Laboratory, The First Affiliated Hospital of Soochow University, Suzhou, Jiangsu, \\ China; ${ }^{2}$ Department of Neurosurgery, General Hospital of Xuzhou Mining Group, The Second Affiliated Hospital of Xuzhou Medical University, \\ Xuzhou, Jiangsu, China
}

*Correspondence: zhouyouxin@suda.edu.cn

${ }^{\#}$ Contributed equally to the work.

Received June 13, 2018 / Accepted August 3, 2018

\begin{abstract}
Glioma is the most common sub-type of brain tumor. Due to the presence of stem-like cells, it is characterized by poor prognosis, aggressive ability and high post-surgical recurrence rates. Hence, there is critical need to identify molecular mechanisms of glioma stem-like cells. We found a novel lncRNA in the ZNF281 gene and named it lncRNA-ZNF281. We detected the expression of lncRNA-ZNF281 in glioma stem-like cells (U251s), the glioma cell line (U251) and also in normal brain tissue. The expression of lncRNA-ZNF281 was lower in glioma stem-like cells (U251s) and this indicates that lncRNAZNF281 can regulate the self-renewal capacity of glioma stem-like cells and stem cell marker expression. Most significantly, lncRNA-ZNF281 inhibits the invasion of glioma stem-like cells by regulating the expression of the NF- $\kappa$ B1 signaling pathway. Our data demonstrates that lncRNA-ZNF281 inhibits the self-renewing ability and invasion of GSCs in vitro and in vivo and can reduce tumorigenicity in the glioma stem-like cell (U251s). The underlying mechanisms may involve the regulation of stem cell markers (CD133, Nestin, OCT4 and Nanog) to reduce the self-renewal ability and regulate the NF- $\kappa$ B1 signaling pathway and inhibit U251s glioma stem-like cell invasion. These finding suggest that lncRNA-ZNF281 could be a successful new therapeutic target in glioma.
\end{abstract}

Key words: IncRNA-ZNF281, glioma stem-like cell, stemness, invasion

Gliomas are the most common form of primary brain malignant tumor in adults and they have no effective therapy [1]. Glioma characteristics include rapid progression, aggressive ability and poor prognosis $[2,3]$. In spite of the current treatment strategies which include surgery, radiation and chemotherapy, glioma patient prognosis has not significantly improved and the median survival time is only 12-14 months [4]. Therefore, to find novel treatment strategies to treat gliomas, it is critical to decipher the underlying molecular mechanisms of glioma tumorigenesis and progression.

The high post-surgical recurrence rate of glioma is mainly attributed to the existence of cancer stem cells (CSCs) which can promote tumor formation and increase both initiation of their differentiation and proliferation [5-6].

The glioma stem-like cells are a sub-set capable of inducing invasion, metastasis, heterogeneity, and therapeutic resistance $[7,8]$. GSCs are defined as a cell population with the capacity to self-renew, differentiate, and give rise to a new type of cancer. Glioma stem-like cells have been identified by several researchers and numerous markers for glioma have been discovered. These include surface antigens CD133, A2B5 and transcription factors OCT4, Nanog and SOX2. Although many studies have deciphered the signaling pathways that regulate the stemness and self-renewal ability of glioma stem-like cells [9-11], the involvement of long noncoding RNAs in GSC's is largely undeciphered.

Long noncoding RNAs (lncRNAs) are a novel class of RNA transcripts longer than 200 nucleotides and lacking protein-coding potential [12]. Several studies have suggested that lncRNAs are important regulators in cancer development, cell growth and invasion and drug resistance [13, 14], and numerous have been reported associated with glioma progression. LncRNA ZEB1-AS1 has been demonstrated to promote tumorigenesis and be associated with poor prognosis in gliomas [15], and lncRNA-TALNEC2 is 
reported to regulate glioma stem cell tumor growth, stemness and radiation response [16].

Our previous research used gene microarray to study glioma stem-like cell lines SHG-139S and its parent cell line SHG-139 [17] and this revealed a IncRNA molecule, named lncRNA-ZNF281 with 353bp in LNCipedia.org, located in chromosome 1q32.1 in nucleotides 200443207-200443559. The lncRNA-ZNF281 expression was down-regulated in glioma stem-like cells compared to normal brain tissue and glioma cell lines. Herein, we determine the molecular mechanism of lncRNA-ZNF281 in glioma stem-like cells, perform in vitro and in vivo experiments and establish its involvement in glioma stem-like cell self-renewal, stemness and invasion.

\section{Patients and methods}

Patient and sample collection. Normal brain tissue was harvested from 5 patients with cranio-cerebral injury. Human brain glioma tissue specimens came from 22 glioma patients including 7 cases of WHO grades II, 8 cases of WHO grades III and 7 cases of the WHO grades IV. Tissue samples were obtained from January 2015 to July 2017 from the Department of Neurosurgery of the First Affiliated Hospital of Soochow University. All tissue samples were immediately collected and stored in liquid nitrogen after resection from patients and then used for analysis. Informed consent was obtained from the patient or patient family members and the study was approved by the local ethics committee of our hospital.

Cell culture. Glioma cell lines U251 was purchased from the Cell Bank of Chinese Academy of Science (Shanghai). Glioma stem-like cells (U251s) were isolated from the U251 cell line. U251 cells were maintained in Dulbecco's Modified Eagle's Medium (DMEM, Hyclone, Thermo Fisher Scientific, Waltham, MA, USA) supplemented with $100 \mathrm{U} / \mathrm{ml}$ of penicillin, $100 \mu \mathrm{g} / \mathrm{ml}$ of streptomycin, and $10 \%$ fetal bovine serum (FBS, Gibco) at $37^{\circ} \mathrm{C}$ and humidified atmosphere of 5\% CO2. The glioma stem-like cell line U251s was cultured in DMEM/F12 containing $20 \mathrm{ng} / \mathrm{ml}$ basic fibroblast growth factor (bFGF Sigma), B27 supplement (stock $50 \times$, Sigma), $20 \mathrm{ng} / \mathrm{ml}$ epidermal growth factor (Sigma), $100 \mathrm{U} / \mathrm{ml}$ penicillin and $100 \mathrm{U} / \mathrm{ml}$ streptomycin (Invitrogen) and cultured at $37^{\circ} \mathrm{C}$ in a humidified atmosphere of $95 \%$ air and $5 \% \mathrm{CO}_{2}$.

Real time quantitative polymerase chain reaction (RT-qPCR) analysis. Total RNA was extracted using the Trizol reagent method. Reverse transcription in $20 \mu \mathrm{l}$ was preformed following the Applied Bio-systems protocol. Primers were synthesized by Sangon Biotech (Shanghai). SYBR Green I qRT-PCR kit (Applied LightCycler480) was used to analyze the mRNA expression levels of lncRNAZNF281, EZH2, SOX2, OCT4, Nanog, Nestin and CD133. The expression of GAPDH was used as the endogenous control. Primer sequences are shown in Supplementary Table S1. The relative expression of mRNA was calculated using the comparative threshold cycle $(\mathrm{Ct})^{(2-\Delta \Delta \mathrm{Ct})}$ method. Samples were analyzed in triplicate.

Construction of over-expressing IncRNA-ZNF281 glioma stem-like cell line U251s. Lentiviral vector was used to construct lncRNA-ZNF281-over-expressing glioma stem-like cells. The lentiviral vector derived from HIV-1 with lncRNA-ZNF281 was designed by GenePharma (Suzhou, China). Glioma stem-like cell line U251s was infected with "enhanced infection solution" to increase transfection efficiency.

Transwell system. IncRNA-ZNF281-U251s (lncRNAZNF281-transfected U251s cells) and lncRNA-NC-U251s (control vector-transfected U251s cells) were cultured in 6-well inserts in the transwell system. Transfected cells were transferred to matrigel-coated invasion chambers (24-well insert, $8 \mathrm{~mm}$ pore size, $\mathrm{BD}$ ) in serum-free DMEM/F12. DMEM/F12 containing 10\% FBS was added as a chemoattractant to the lower chambers. Cells that did not migrate from the top wells were removed using a cotton wrap and cells that migrated to the lower membrane surface were fixed with $4 \%$ formaldehyde and stained with $0.2 \%$ crystal violet. Migrated cells were imaged and manually counted using five randomly selected fields under a microscope.

Spheroid formation assay. Single cell suspensions were washed twice with serum-free Phosphate Buffer Solution (PBS) and plated in 24-well ultra-low attachment plates (Corning, Steuben County, NY, USA) at a density of 250 cells in culture media supplemented with $20 \mathrm{ng} / \mathrm{ml}$ basic fibroblast growth factor (Sigma), B27 supplement (stock 50×, Sigma), $20 \mathrm{ng} / \mathrm{ml}$ epidermal growth factor (Sigma), $100 \mathrm{U} / \mathrm{ml}$ penicillin and $100 \mathrm{U} / \mathrm{ml}$ streptomycin (Invitrogen). The cells were incubated at $37^{\circ} \mathrm{C}$ in a humidified atmosphere of $95 \%$ air and $5 \% \mathrm{CO}_{2}$.

Immunofluorescence. Cells were plated on poly-Llysine-coated glass coverslips and fixed with $4 \%$ paraformaldehyde. The cells were then washed 3 times with PBS, with 5 min incubations per wash and then permeabilized with $0.1 \%$ Triton X-100 for $10 \mathrm{~min}$ and subsequently blocked with goat serum. Primary antibodies CD133 (rabbit antihuman, Abcam), EZH2 (rabbit anti human, Cell Signaling Technology), Nestin (rabbit anti-human, Abcam), SOX2 (rabbit anti-human, Abcam), OCT4 (rabbit anti-human, Abcam) and Nanog (rabbit anti-human, Abcam) were incubated (concentration used per manufacturer's instructions) overnight at $4{ }^{\circ} \mathrm{C}$. Next day, the cells were washed 3 times with PBS (with 15 minutes of incubation per wash) and then incubated with fluorescent secondary antibodies at room temperature protected from light for $1 \mathrm{~h}$. Cells were then counterstained with DAPI for $1 \mathrm{~min}$ before being sealed with mounting medium. The cells were analyzed under fluorescent microscopy (Olympus, Japan).

Western blotting. Total protein was extracted from cells using RIPA buffer and protein was quantified using the BCA (bicinchoninic acid) assay kit (Beyotime, Shanghai, China). Protein samples were separated using 10\% SDS-PAGE 
gel and then transferred onto PVDF membranes. PVDF membranes were incubated with the relevant primary antibodies overnight at $4^{\circ} \mathrm{C}$. Membranes were then washed and incubated for $2 \mathrm{~h}$ with horseradish peroxidase (HRP)conjugated anti-rabbit secondary antibodies (Prosci Inc. 1:3,000; Poway, CA, USA), followed by detection and visualization by ECL Western blotting detection reagents (Pierce antibodies, Thermo Fisher, USA).

Xenograft tumor models. All animal experiments were carried out in accordance with institutional guidelines and regulations of the institute. Female BALB/c nude mice were purchased from the China Academy of Sciences (Shanghai) and randomly divided into two groups (6 mice per group). Glioma stem-like cells were counted and then re-suspended to $1 \times 10^{5}$ cells $/ \mu$ l using PBS. The cells were then subcutaneously implanted into the right frontal lobe of the brain. Mice were observed after injection to monitor the size of subcutaneous and weight of intracranial xenografts. For intracranial xenografts, when mice developed cachexia, they were euthanized and whole brain tissue was removed and fixed in formalin.
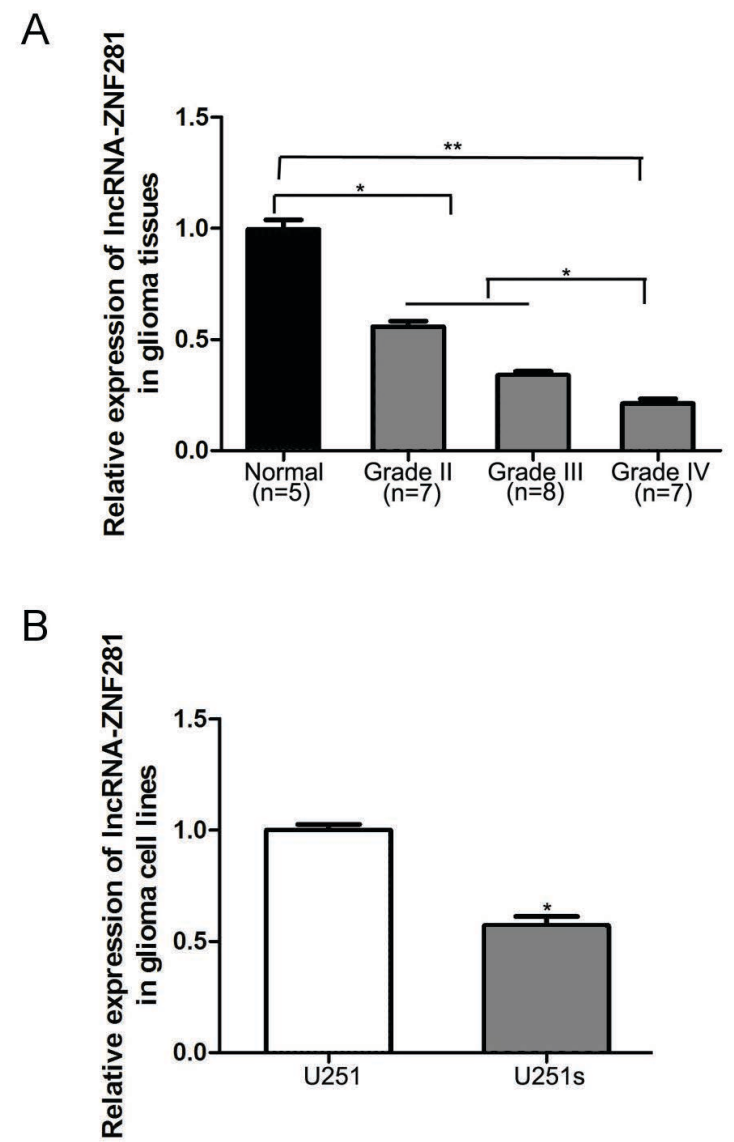

Immunohistochemistry. Brain tissues were cut into $4 \mu \mathrm{m}$ sections by microtome. Immunohistochemistry was performed on formalin-fixed paraffin-embedded sections. Endogenous peroxidase activity was blocked for $15 \mathrm{~min}$ with $0.3 \%$ hydrogen peroxide after hydration. Antigen retrieval was performed using $10 \mathrm{mM}$ sodium citrate buffer at $\mathrm{pH} 6$ for $10 \mathrm{~min}$ at $100^{\circ} \mathrm{C}$. Tissue sections were then blocked with $5 \%$ BSA, and incubated with primary antibody - anti-Ki67 (Abcam), anti-MMP2 (Abcam), anti-MMP9 (Abcam), or anti-NF- $\mathrm{kB} 1$ (Abcam) antibody at $4{ }^{\circ} \mathrm{C}$ overnight. Sections were stained using the Cell and Tissue Staining Kit HRP-DAB (R\&D Systems, MN, USA), according to the manufacturer's instructions and immunohistochemistry was performed with known positive and negative tumor controls.

\section{Results}

Expression of lncRNA-ZNF281 is lower in glioma stemlike cells (U251s) than in normal brain tissues and the glioma cell line (U251). Real time quantitative polymerase chain reaction (RT-qPCR) was used to measure the expres-

C

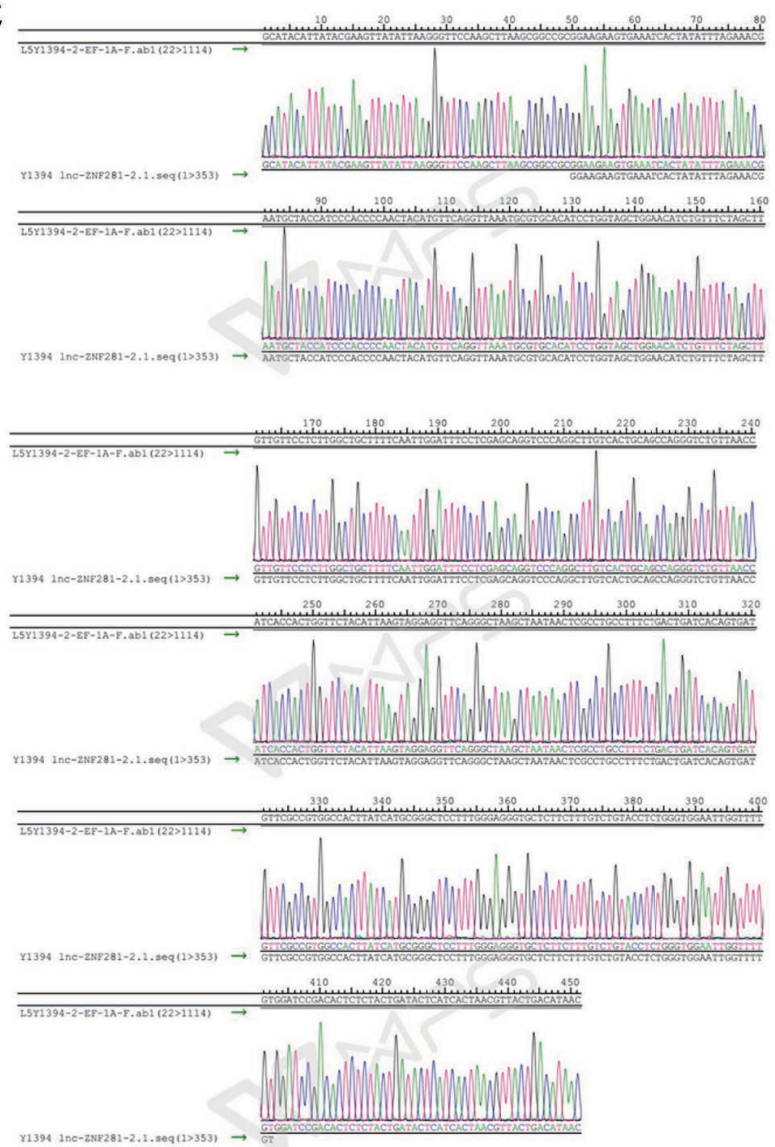

Figure 1. The expression of IncRNA-ZNF281 in glioma tissues and glioma stem-like cells (U251s). A) The expression of lncRNA-ZNF281 was lower in glioma tissues than in normal brain tissues $\left({ }^{*} \mathrm{p}<0.01 ;{ }^{*} \mathrm{p}<0.05\right)$. B) The expression of IncRNA-ZNF281 was lower in glioma stem-like cells U251s than in glioma cell line U251 and normal brain tissues $\left({ }^{*} \mathrm{p}<0.05\right)$. C) The complete gene sequence to construct lentiviral vector. 
sion of lncRNA-ZNF281 in glioma tissues, CD133+ glioma stem cells U251s, glioma cell line U251 and normal brain tissues. IncRNA-ZNF281 expression in glioma tissues was lower than in normal brain tissues and decreased gradually with degree of tumor malignancy $(p<0.05$, Figure $1 A)$. As expected, IncRNA-ZNF281 expression in the glioma stem-like cell U251s was lower than in glioma cell line U251 $(\mathrm{p}<0.05$, Figure 1B). This suggests that IncRNA-ZNF281 regulates stem-like characteristics in glioma. We therefore constructed a lentiviral vector expressing lncRNA-ZNF281 (Figure 1C) to investigate its role in glioma.

Transfection efficiency of lncRNA-ZNF281 overexpressing glioma stem-like U251s cells. We constructed a stable over-expression of lncRNA-ZNF281 in U251s to perform functional validation. We detected transfection efficiency using fluorescence microscopy and flow cytometry (Figures 2A, B) and used RT-qPCR to determine the expression level of lncRNA-ZNF281 in lncRNA-ZNF281-U251s and lncRNA-NC-U251s cells. The expression levels of lncRNAZNF281 in lncRNA-ZNF281-U251s cells were significantly higher than in IncRNA-NC-U251s and untreated glioma stem-like cell U251s ( $\mathrm{p}<0.01$, Figure $2 \mathrm{C}$ ).
LncRNA-ZNF281 inhibited the self-renewal capacity and expression of stem cell markers in glioma stem-like U251s cells. We analyzed the expression of stem cell markers to determine the effect of lncRNA-ZNF281 over-expression in glioma stem-like cells. Using immunofluorescent assays, we found that lncRNA-ZNF281 could inhibit the expression of stem markers CD133, Nestin, OCT4 and Nanog. However, the expression of EZH2 in lncRNA-ZNF281-U251s was higher than in lncRNA-NC-U251s, while SOX2 expression had no significant difference in the two groups (Figure 3A). In addition, mRNA and protein expression of these stem cell markers were consistent with immunofluorescent data (Figures 3B, C). Glioma stem-like cells have the capacity to self-renew and proliferate. Using spheroid formation assays, we demonstrated that IncRNA-ZNF281 could inhibit the capacity of self-renewal and proliferation in U251s $(\mathrm{p}<0.05$, Figure 3D).

IncRNA-ZNF281 reduces the invasive ability of glioma stem-like cells (U251s) by regulating the NF- $\kappa$ B1 signaling pathway. We used the transwell system to assess the effect of lncRNA-ZNF281 over-expressed glioma stem-like cell invasion. Over-expression of lncRNA-ZNF281 resulted in
A

Expression of IncRNA-ZNF281
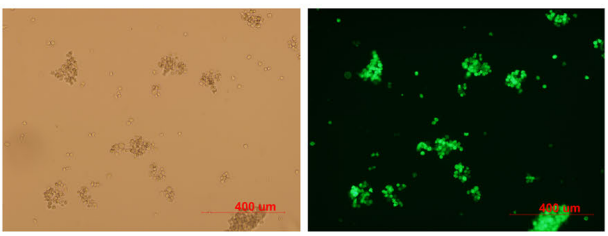

IncRNA-ZNF281-U251s

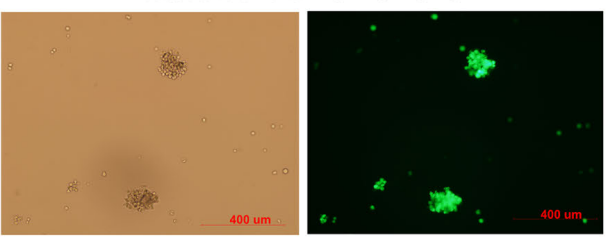

IncRNA-NC-U251s
C

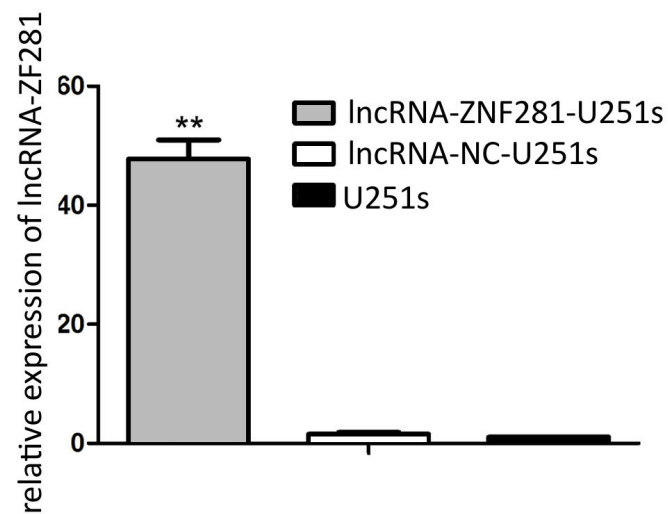

B

Expression of IncRNA-ZNF281

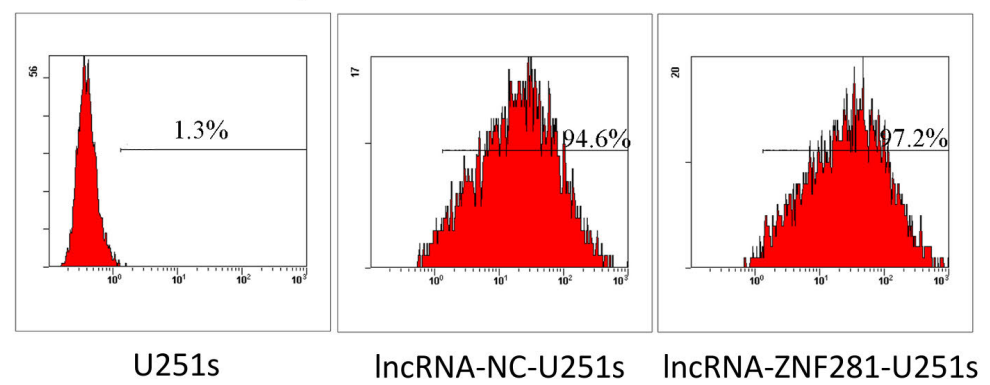

Figure 2. Construct of the lncRNA-ZNF281-overexpressed glioma stem-like cells U251s. A, B) The transfection efficiency is more than 90\% determined by fluorescence microscopy and flow cytometry. C) The expression of lncRNA-ZNF281 in lncRNA-ZNF281-U251s was significantly higher than IncRNA-NC-U251s and untreated glioma stem-like cell U251s $\left({ }^{* *} \mathrm{p}<0.01\right)$. NC: negative control group 
A

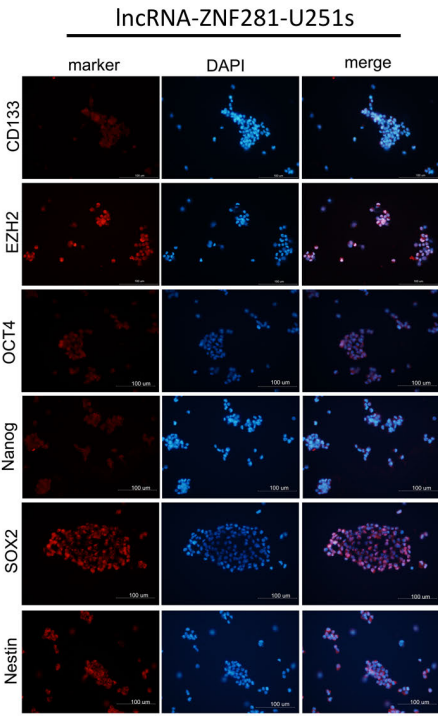

B

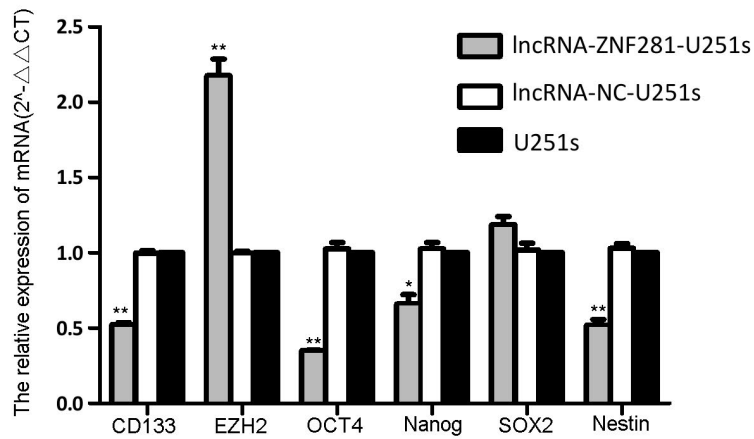

InCRNA-NC-U251s
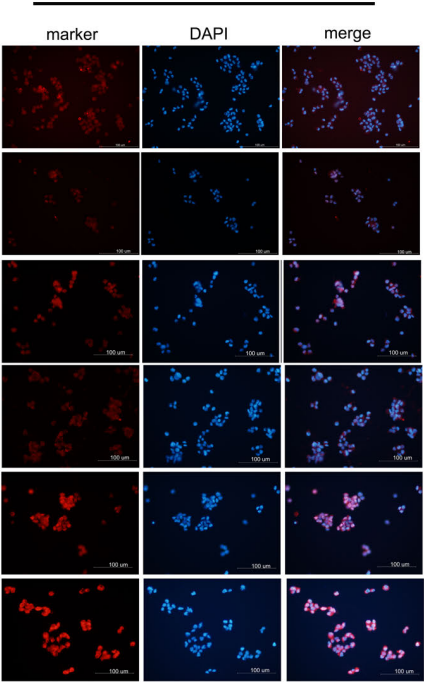
Nestin, OCT4 and Nanog, but the expression of EZH2 in lncRNA-ZNF281-U251s was higher than lncRNA-NC-U251s and the SOX2 expression had no significant change in two groups. B, C) The mRNA and protein expression of stem marker acquired the same result. D) The self-renew capacity was inhibited by lncRNA-ZNF281 ( $\left.{ }^{*} \mathbf{p}<0.05\right)$. NC: negative control group

significantly less migrated cells than in lncRNA-NC and untreated cells $(\mathrm{p}<0.05$, Figures $4 \mathrm{~A}, \mathrm{~B})$. To understand the molecular mechanism, we analyzed the invasive related proteins MMP9, MMP2 and NF- $\kappa$ B1 by Western blot analysis. Our results demonstrate that lncRNA-ZNF281 inhibited the expression of NF- $\kappa \mathrm{B} 1, \mathrm{MMP} 9$ and MMP2 to regulate invasion of glioma stem-like cells (Figure 4C).

LncRNA-ZNF281 reduces glioma growth and inhibits the expression of the proliferative protein (ki-67) in subcutaneous xenograft tumor models. To investigate the effect of lncRNA-ZNF281 in tumorigenesis, we established a subcutaneous xenograft tumor model (Figure 5A). Over-expression of IncRNA-ZNF281 reduced the size of tumors compared with the control groups $(p<0.05$, Figure $5 B)$. In addition, the expression of the proliferative protein (Ki-67) in brain xenograft tumor models was inhibited by lncRNA-ZNF281 (Figure 5C).
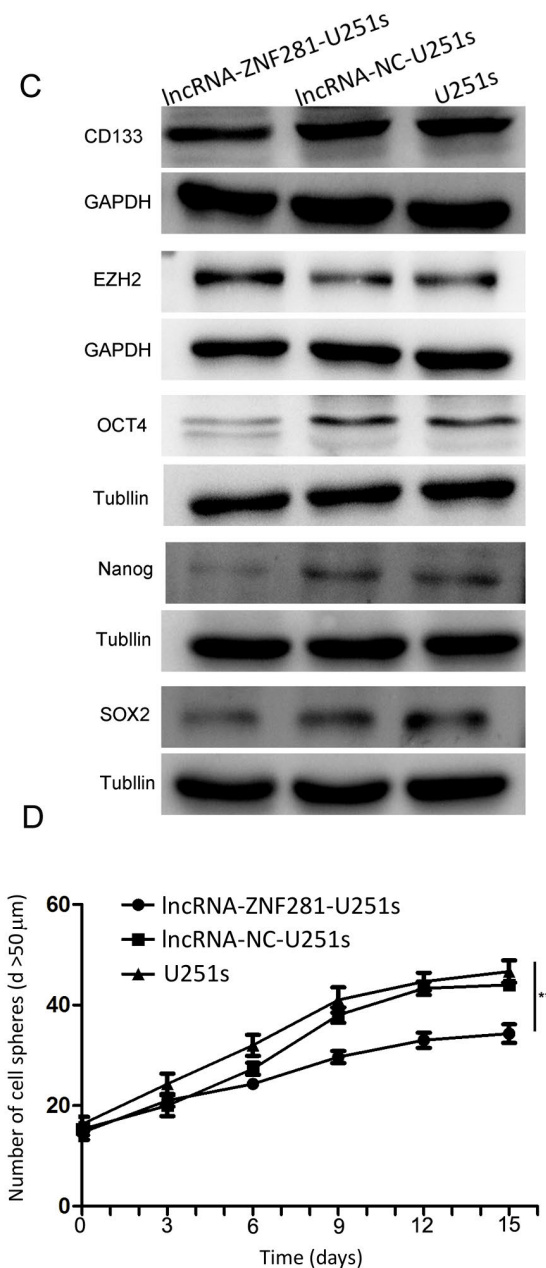
A

IncRNA-ZNF281-U251s

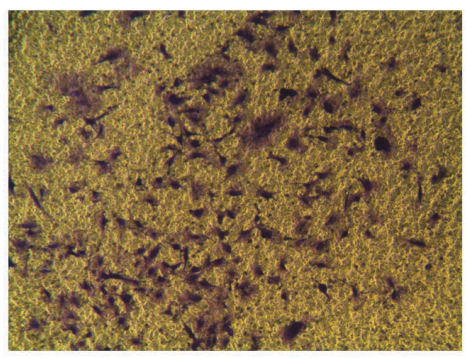

B

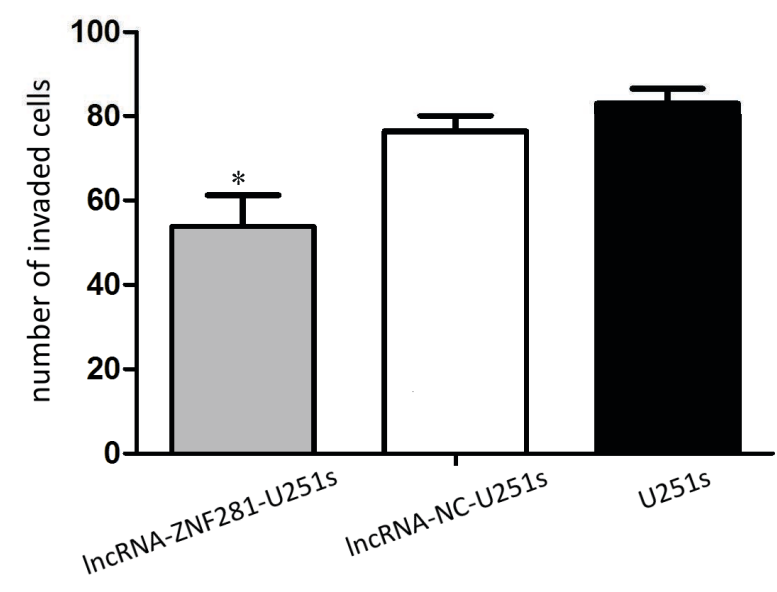

U251s

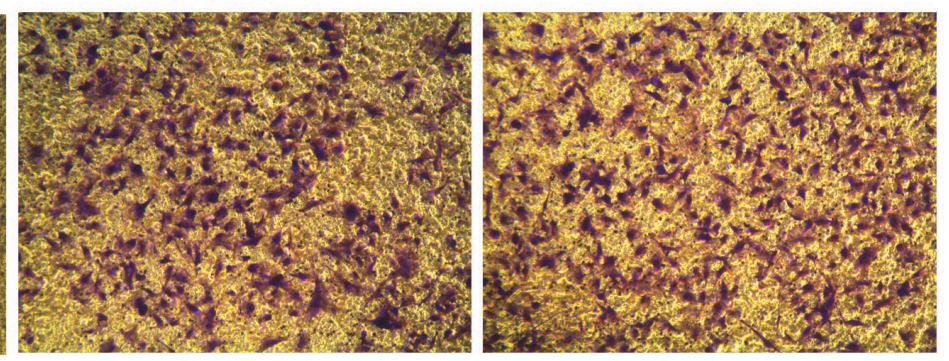

Figure 4. IncRNA-ZNF281 reduces invasive ability in glioma stem-like cells U251s. A, B) The numbers of invasive cells with lncRNA-ZNF281 were significantly less than those with IncRNA-NC and untreated cells $\left({ }^{*} \mathbf{p}<0.05\right)$. C) The protein expression of MMP2, MMP9, NF-кB1 was obviously reduced by IncRNAZNF281. NC: negative control group
A

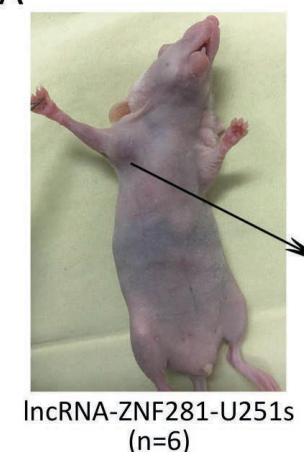

C

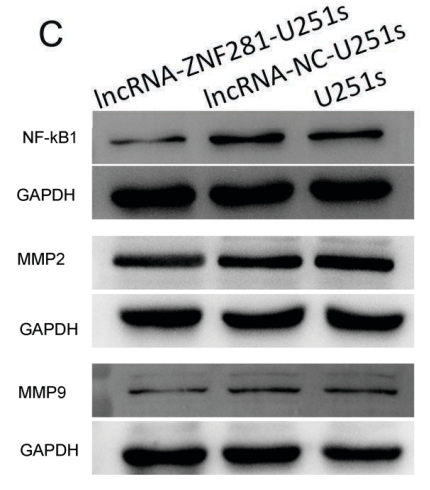

B

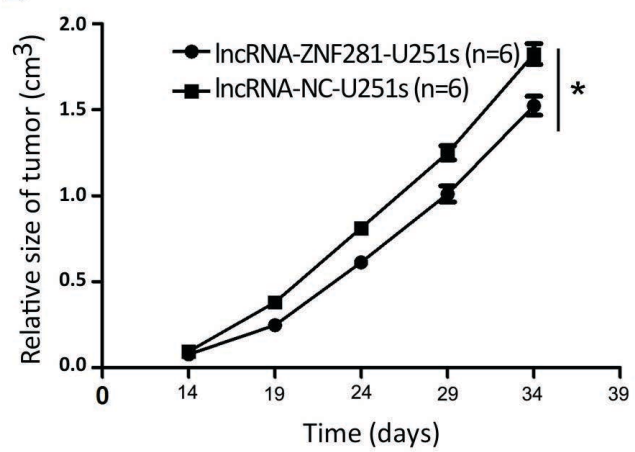

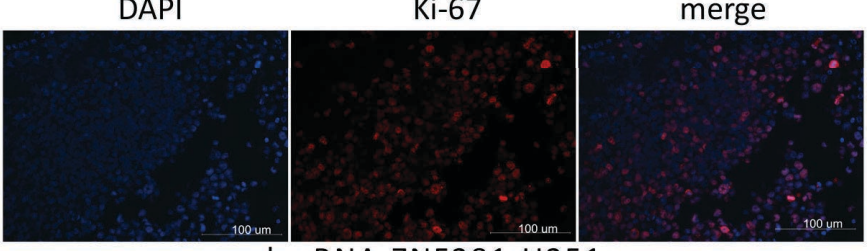

IncRNA-ZNF281-U251s

Figure 5. IncRNA-ZNF281 can reduce the growth of glioma stem-like cells in vivo. A, B) IncRNA-ZNF281 can reduce the size of tumor in subcutaneously xenograft tumor models $\left.\left({ }^{*} \mathbf{p}<0.05\right) . \mathrm{C}\right)$ The expression of Ki-67 protein was inhibited by IncRNAZNF281. NC: negative control group

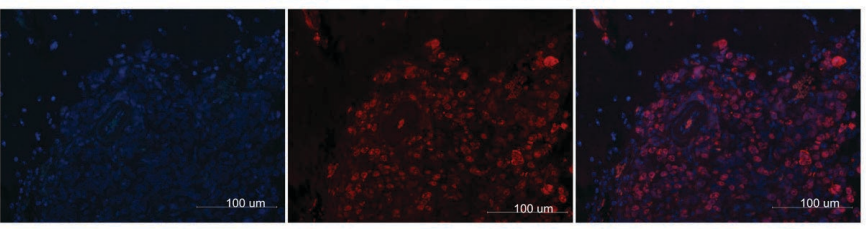

IncRNA-NC-U251s 

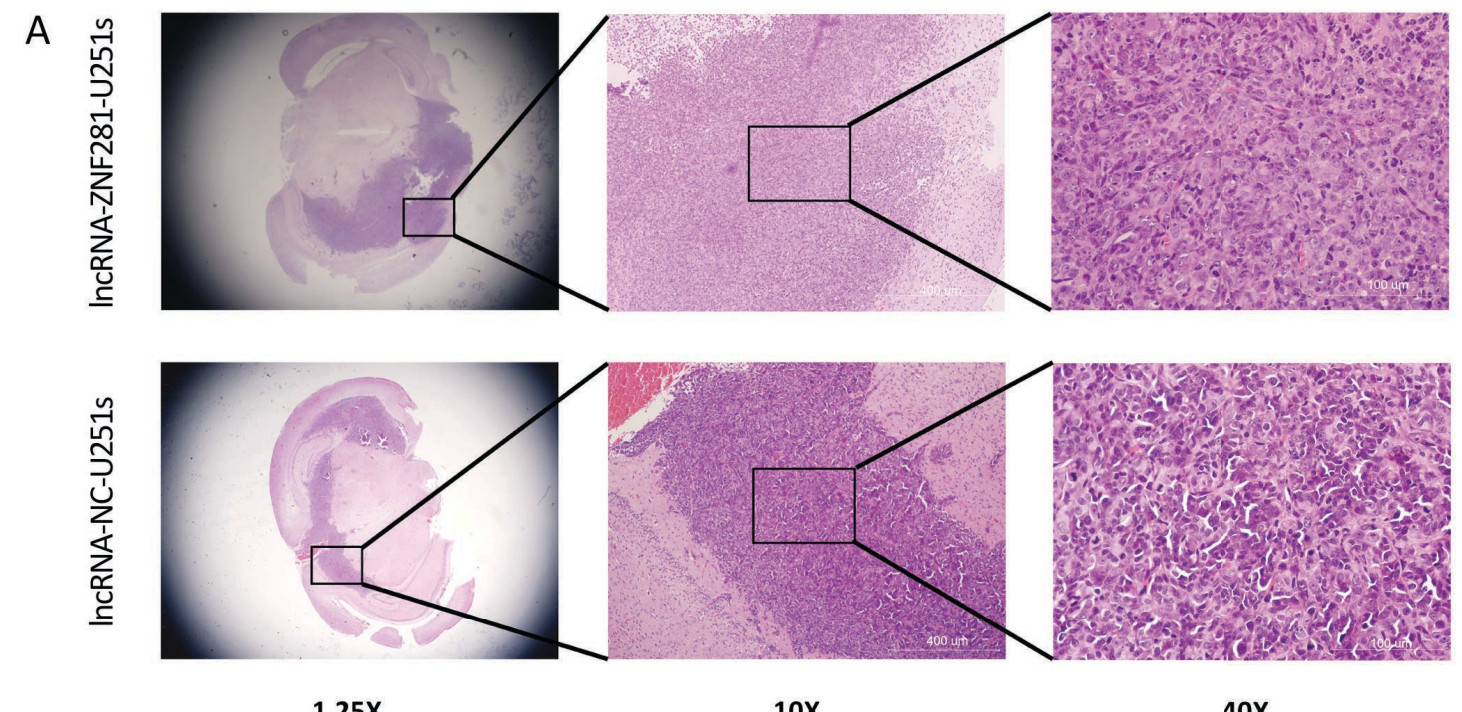

$1.25 X$

$10 \mathrm{X}$

$40 \mathrm{X}$

B

Ki-67

Ki-67
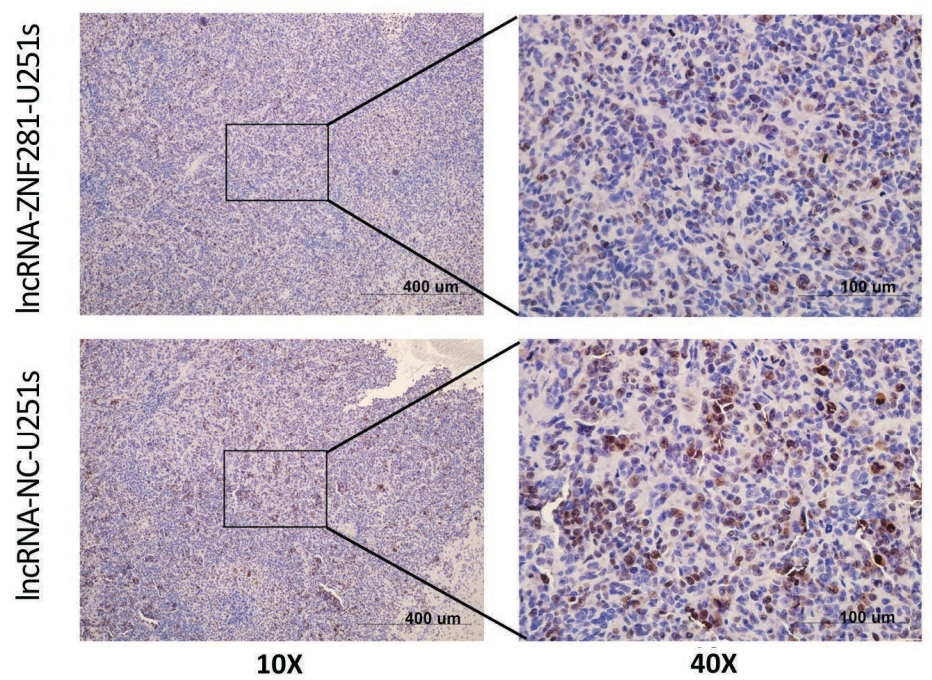

Figure 6. A) HE staining to test tumor formation in nude mouse brain. B) Immunohistochemistry showed that the expression of Ki-67 was reduced. NC: negative control group

with glioma is disappointing. Several studies have suggested that stem cells are the initiating cells for glioma and are the primary reason for the high post-surgical recurrence rate [18]. In addition, glioma stem-like cells have the capacity to promote invasion and migration of gliomas [19]. Based on the hypothesis that cancer stem cells are multipotent with ability to indefinitely self-renew and asymmetrically divide [20], it is essential to eliminate glioma stem cells in patient treatment.

Identifying cancer stem cells is the foremost target in researching its molecular mechanism, and several cellsurface markers can currently be used to isolate glioma stem cells. CD133 and prominin-1 were the first cell-surface markers identified to distinguish glioma stem cells and glioma differentiated cells [21]. In addition, A2B5 [22, 23], CD44 [24], Nestin [25] and transcription factors OCT4, Nanog and SOX2 [26] are critical for glioma stem cells to self-renew, grow and promote invasion. Therefore, these capacities should be inhibited if we reduce the expression of the various markers. For example, H19 knocked-down glioma cell lines showed significant reduced expression of CSC markers CD133, Nanog, Oct4 and SOX2 and decreased capacity in glioma stem cells [27].

To effectively eliminate glioma stem-like cells requires unequivocal understanding of glioma stem-like cell features. With the identification of lncRNAs in cancers, several studies have demonstrated that lncRNAs can regulate the characteristics and capacity of cancer stem cells by various 

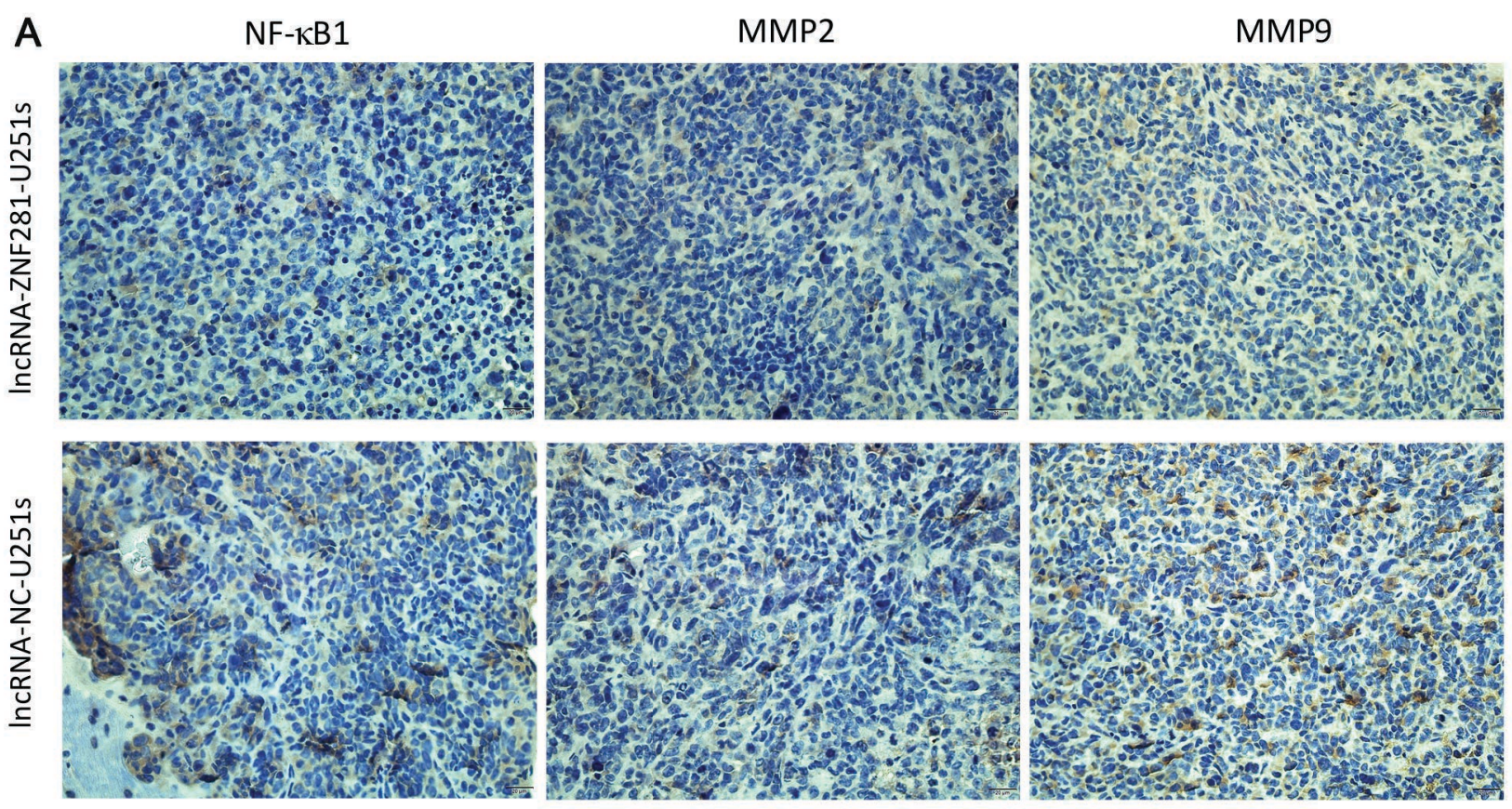

B
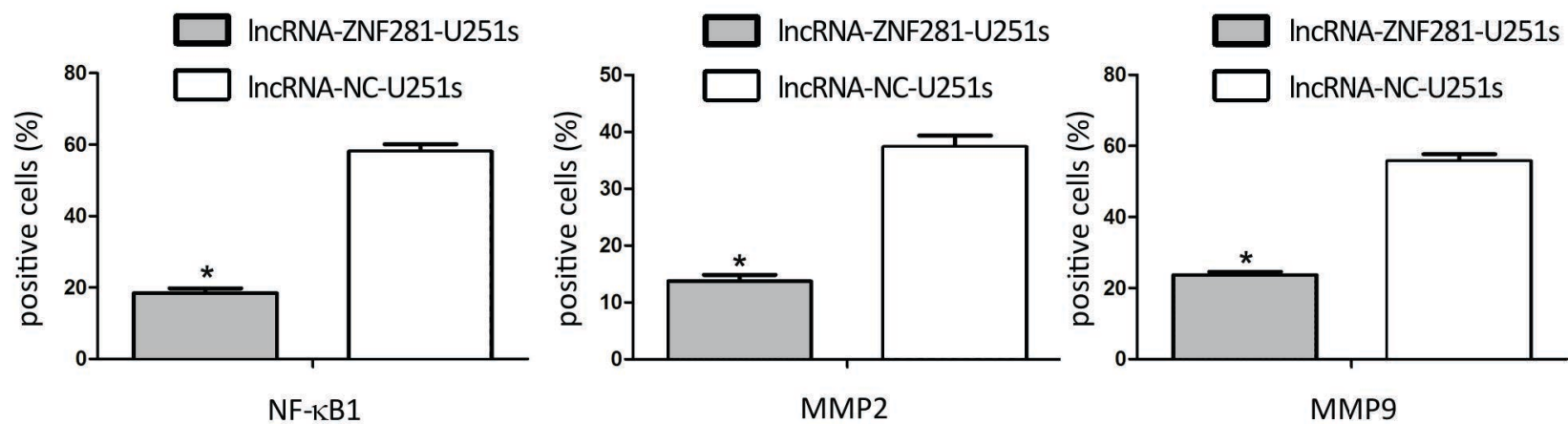

Figure 7. A, B) lncRNA-ZNF281 reduced the expression of NF-кB1, MMP2 and MMP9 in brain xenograft tumor. NC: negative control group

signaling pathways. In hepatic cell cancer, IncRNMA-CATA1 promotes proliferation and cancer stem cell-like properties of liver cancer by regulating CAMTA1 [28].

Certain lncRNAs can influence stemness, invasion, migration and tumorigenesis in glioma. For example, lncRNAptcsc3 inhibits the proliferation and invasion of glioma cells by suppressing the Wnt/ $\beta$-catenin signaling pathway [29] and lncRNA-MALAT1 maintains the stemness of glioma stem cells [30].

Our previous study discovered a new lncRNAs (lncRNAZNF281) which had reduced expression in glioma stemlike cells compared to normal brain tissues and glioma cell lines, and results suggested that lncRNA-ZNF281 acts as a tumor suppressor gene to regulate progression of gliomas. Herein, we found that lncRNA-ZNF281 inhibits the stemlike properties of glioma stem cells because lncRNA-ZNF281 over-expression by lentiviral vectors in human glioma stem-like cells U251s established significantly reduced selfrenewal capacity and cell growth. While the expression of CD133, Nestin, OCT4 and Nanog glioma stem-like cell markers was reduced in lncRNA-ZNF281 over-expressed cells, EZH2 expression was increased and SOX2 expression made no obvious difference. This demonstrates that lncRNAZNF281 inhibits the expression of CD133, Nestin and OCT4 to regulate the stemness of GSCs.

We also demonstrated that IncRNA-ZNF281 reduced GSC invasive ability and down-regulated NF-kB1 and MMP9 protein expression. The NF- $\mathrm{kB} 1$ signaling pathway has an important role in cancer invasion and migration and NF- $\kappa \mathrm{B}$ activation is associated with cancer. Here, NF- $\kappa B$ activity was much higher in GBM tissues compared to normal tissues [31] and it was associated with glioma grade [32]. Further, 
the MMP9 and MMP2 key enzymes required for invasion are NF- $\kappa \mathrm{B}$-regulated genes, and their levels increase with glioma tumor progression [33].

In conclusion, we demonstrated herein that lncRNAZNF281 regulates the invasion capacity of GSCs via the NF- $\kappa \mathrm{B} 1$ signaling pathway, and consistent with our in vitro findings, we established that it also reduced CSC growth and invasion in vivo by regulating the NF- $\kappa \mathrm{B} 1$ signaling pathway. lncRNA-ZNF281 also reduced the expression of CD133 and OCT4 self-renewal related factors in glioma stem-like cells, decreased the capacity of self-renewal in vitro and reduced invasive ability by regulating the NF- $\kappa \mathrm{B} 1$ signaling pathway in both in vitro and in vivo.

Finally, our combined results indicate that IncRNAZNF281 regulates glioma stem cell-like phenotypes and inhibits stem-like cell invasion in glioma.

Supplementary information is available in the online version of the paper.

Acknowledgments: We thank our central lab for providing technical instruction and assistance. We thank Cell Bank Type Culture Collection of the Chinese Academy of Sciences (Shanghai, China) for offering us glioma cells line. We thank The First Affiliated Hospital of Soochow University for providing us with glioma samples. This study was supported by the National Natural Science Foundation of China (Grant No. NSFC81372689).

\section{References}

[1] SURAWICZ TS, MCCARTHY BJ, KUPELIAN V, JUKICH PJ, BRUER JM et al. Descriptive epidemiology of primary brain and CNS tumors: results from the Central Brain Tumor Registry of the United States, 1990-1994. Neuro Oncol 1999; 1: 14-25. https://doi.org/10.1093/neuonc/1.1.14

[2] STEEG PS, CAMPHAUSEN KA, SMITH QR. Brain metastases as preventive and therapeutic targets. Nat Rev Cancer 2011; 11: 352-363. https://doi.org/10.1038/nrc3053

[3] HEGI ME, DISERENS AC, GORLIA T, HAMOU MF, DE TRIBOLET $\mathrm{N}$ et al. MGMT gene silencing and benefit from temozolomide in glioblastoma. N Engl J Med 2005; 352: 997-1003. https://doi.org/10.1056/NEJMoa043331

[4] GALLEGO O. Nonsurgical treatment of recurrent glioblastoma. Curr Oncol 2015; 22: e273-281. https://doi.org/10.3747/ Co.22.2436

[5] DALERBA P, CHO RW, CLARKE MF. Cancer stem cells: models and concepts. Annu Rev Med 2007, 58: 267-284. https://doi.org/10.1146/annurev.med.58.062105.204854

[6] CLARKE MF, FULLER M. Stem cells and cancer: two faces of eve. Cell 2006, 124: 1111-1115. https://doi.org/10.1016/j. cell.2006.03.011

[7] VESCOVI AL, GALLI R, REYNOLDS BA. Brain tumour stem cells. Nat Rev Cancer 2006; 6: 425-436. https://doi. org/10.1038/nrc1889
[8] BEIER D, SCHRIEFER B, BRAWANSKI K, HAU P, WEIS $\mathrm{J}$ et al. Efficacy of clinically relevant temozolomide dosing schemes in glioblastoma cancer stem cell lines. J Neurooncol 2012; 109: 45-52. https://doi.org/10.1007/s11060-012-08784

[9] LI Z, BAO S, WU Q, WANG H, EYLER C et al. Hypoxiainducible factors regulate tumorigenic capacity of glioma stem cells. Cancer Cell 2009; 15: 501-513. https://doi. org/10.1016/j.ccr.2009.03.018

[10] ZHU TS, COSTELlO MA, TALSMA CE, FLACK CG, CROWLEY JG et al. Endothelial cells create a stem cell niche in glioblastoma by providing NOTCH ligands that nurture self-renewal of cancer stem-like cells. Cancer Res 2011; 71: 6061-6072. https://doi.org/10.1158/0008-5472.can-10-4269

[11] GALAN-MOYA EM, LE GUELTE A, LIMA FERNANDES E, THIRANT C, DWYER J et al. Secreted factors from brain endothelial cells maintain glioblastoma stem-like cell expansion through the mTOR pathway. EMBO Rep 2011; 12: 470-476. https://doi.org/10.1038/embor.2011.39

[12] IYER MK, NIKNAFS YS, MALIK R, SINGHAL U, SAHU A et al. The landscape of long noncoding RNAs in the human transcriptome. Nat Genet 2015; 47: 199-208. https:// doi.org/10.1038/ng.3192

[13] JI P, DIEDERICHS S, WANG W, BOING S, METZGER $\mathrm{R}$ et al. MALAT-1, a novel noncoding RNA, and thymosin beta4 predict metastasis and survival in early-stage nonsmall cell lung cancer. Oncogene 2003; 22: 8031-8041. https://doi. org/10.1038/sj.onc. 1206928

[14] LI C, ZHOU L, HE J, FANG XQ, ZHU SW et al. Increased long noncoding RNA SNHG20 predicts poor prognosis in colorectal cancer. BMC Cancer 2016; 16: 655. https://doi. org/10.1186/s12885-016-2719-x

[15] LV QL, HU L, CHEN SH, SUN B, FU ML et al. A long noncoding RNA ZEB1-AS1 promotes tumorigenesis and predicts poor prognosis in glioma. Int J Mol Sci 2016; 17. https://doi.org/10.3390/ijms17091431

[16] BRODIE S, LEE HK, JIANG W, CAZACU S, XIANG C et al.The novel long non-coding RNA TALNEC2, regulates tumor cell growth and the stemness and radiation response of glioma stem cells. Oncotarget 2017; 8: 31785-31801. https:// doi.org/10.18632/oncotarget.15991

[17] LI Y, WANG H, SUN T, CHEN J, GUO L et al. Biological characteristics of a new human glioma cell line transformed into A2B5(+) stem cells. Mol Cancer 2015; 14: 75. https:// doi.org/10.1186/s12943-015-0343-Z

[18] CHEN J, LI Y, YU TS, MCKAY RM, BURNS DK et al. A restricted cell population propagates glioblastoma growth after chemotherapy. Nature 2012; 488: 522-526. https://doi. org/10.1038/nature11287

[19] GALLI R, BINDA E, ORFANELLI U, CIPELLETTI B, GRITTI A et al. Isolation and characterization of tumorigenic, stem-like neural precursors from human glioblastoma. Cancer Res 2004; 64: 7011-7021. https://doi. org/10.1158/0008-5472.CAN-04-1364

[20] VESCOVI AL, GALLI R, REYNOLDS BA. Reynolds. Brain tumour stem cells. Nat Rev Cancer 2006; 6: 425-436. https:// doi.org/10.1038/nrc1889 
[21] SINGH SK, HAWKINS C, CLARKE ID, SQUIRE JA, BAYANI J et al. Identification of human brain tumour initiating cells. Nature 2004; 432: 396-401. https://doi.org/10.1038/nature 03128

[22] OGDEN AT, WAZIRI AE, LOCHHEAD RA, FUSCO $\mathrm{D}$, LOPEZ $\mathrm{K}$ et al. Identification of A2B5+CD133- tumor-initiating cells in adult human gliomas. Neurosurgery 2008; 62: 505-514. https://doi.org/10.1227/01. neu.0000316019.28421.95

[23] TCHOGHANDJIAN A, BAEZA N, COLIN C, CAYRE M, METELLUS P et al. A2B5 cells from human glioblastoma have cancer stem cell properties. Brain Pathol 2010; 20: 211221. https://doi.org/10.1111/j.1750-3639.2009.00269.x

[24] ANIDO J, SAEZ-BORDERIAS A, GONZALEZ-JUNCA A, RODON L, FOLCH G et al. TGF- $\beta$ Receptor Inhibitors Target the CD44(high)/Id1(high) Glioma-Initiating Cell Population in Human Glioblastoma. Cancer Cell 2010; 18: 655-668. https://doi.org/10.1016/j.ccr.2010.10.023

[25] BEXELL D, GUNNARSSON S, SIESJO P, BENGZON J, DARABI A. CD133+ and nestin+ tumor-initiating cells dominate in $\mathrm{N} 29$ and $\mathrm{N} 32$ experimental gliomas. Int J Cancer 2009; 125: 15-22. https://doi.org/10.1002/ijc.24306

[26] GUO Y, LIU S, WANG P, ZHAO S, WANG F et al. Expression profile of embryonic stem cell-associated genes Oct4, Sox2 and Nanog in human gliomas. Histopathology 2011; 59: 763-775. https://doi.org/10.1111/j.1365-2559.2011.03993.

[27] LI W, JIANG P, SUN X, XU S, MA X. Suppressing H19 Modulates Tumorigenicity and Stemness in U251 and U87MG Glioma Cells. Cell Mol Neurobiol 2016; 36: 1219-1227. https://doi.org/10.1007/s10571-015-0320-5
[28] DING LJ, LI Y, WANG SD, WANG XS, FANG F et al. Long Noncoding RNA lncCAMTA1 Promotes Proliferation and Cancer Stem Cell-Like Properties of Liver Cancer by Inhibiting CAMTA1. Int J Mol Sci 2016; 17. https://doi.org/10.3390/ ijms 17101617

[29] XIA S, JI R, ZHAN W. Long noncoding RNA papillary thyroid carcinoma susceptibility candidate 3 (PTCSC3) inhibits proliferation and invasion of glioma cells by suppressing the Wnt/ $\beta$-catenin signaling pathway. BMC Neurol 2017; 17: 30. https://doi.org/10.1186/s12883-017-0813-6

[30] HAN Y, ZHOU L, WU T, HUANG Y, CHENG Z et al. Downregulation of lncRNA-MALAT1 Affects Proliferation and the Expression of Stemness Markers in Glioma Stem Cell Line SHG139S. Cell Mol Neurobiol 2016; 36: 1097-1107. https:// doi.org/10.1007/s10571-015-0303-6

[31] WANG H, WANG H, ZHANG W, HUANG HJ, LIAO WS et al. Analysis of the activation status of Akt, NF- $\kappa$ B, and Stat3 in human diffuse gliomas. Lab Invest 2004; 84: 941-951. https://doi.org/10.1038/labinvest.3700123

[32] ANGILERI FF, AGUENNOUZ M, CONTI A, LA TORRE $D, C A R D A L I S$ et al. Nuclear factor- $\kappa B$ activation and differential expression of survivin and $\mathrm{Bcl}-2$ in human grade 2-4 astrocytomas. Cancer 2008; 112: 2258-2266. https://doi. org/10.1002/cncr.23407

[33] FORSYTH PA, WONG H, LAING TD, REWCASTLE NB, MORRIS DG et al. Gelatinase-A (MMP-2), gelatinase-B (MMP-9) and membrane type matrix metalloproteinase-1 (MT1-MMP) are involved in different aspects of the pathophysiology of malignant gliomas. Br J Cancer 1999; 79: 1828-1835. https://doi.org/10.1038/sj.bjc.6690291 


\section{Novel lncRNA-ZNF281 regulates cell growth, stemness and invasion of glioma stem-like U251s cells.}

X. T. LI, J. C. LI, M. FENG, Y. X. ZHOU, Z .W. DU

Supplemental Material

Suppl. Table 1. The sequences of all primers

\begin{tabular}{ll}
\hline Gene & Primer sequences $\left(\mathbf{5}^{\prime} \rightarrow \mathbf{3}^{\prime} \mathbf{)}\right.$ \\
\hline LncRNA-ZNF281 & Forward:AGGTCCCAGGCTTGTCACT \\
& Reverse: CAGAAAGGCAGGCGAGTTAT \\
CD133 & Forward:ATTGACTTCTTGGTGCTGTTGA \\
& Reverse: GATGGAGTTACGCAGGTTTCTC \\
Nestin & Forward: CTGCTACCCTTGAGACACCTG \\
& Reverse: GGGCTCTGATCTCTGCATCTAC \\
OCT4 & Forward: GTGTTCAGCCAAAAGACCATCT \\
& Reverse: GGCCTGCATGAGGGTTTCT \\
Nanog & Forward: TCCCGAGAAAAGATTAGTCAGCA \\
& Reverse:AGTGGGGCACCTGTTTAACTT \\
SOX2 & Forward: CTCGTGCAGTTCTACTCGTCG \\
& Reverse: AGCTCTCGGTCAGGTCCTTT \\
EZH2 & Forward: AATCAGAGTACATGCGACTGAGA \\
& Reverse: GCTGTATCCTTCGCTGTTTCC \\
GAPDH & Forward: ACC ACA GTC CAT GCC ATC AC \\
& Reverse: TCC ACC ACC CTG TTG CTG TA \\
\hline
\end{tabular}

